\title{
Communication
}

\section{Modes of Fatty Acid Desaturation in Cyanobacteria: An Update}

\section{Dmitry A. Los * and Kirill S. Mironov}

Institute of Plant Physiology, Russian Academy of Sciences, Botanicheskaya Street, Moscow 127276, Russia; E-Mail: ksmironov@gmail.com

* Author to whom correspondence should be addressed; E-Mail: losda@ippras.ru; Tel./Fax: +7-499-977-9372.

Academic Editors: John C. Meeks and Robert Haselkorn

Received: 30 September 2014 / Accepted: 10 February 2015 / Published: 16 February 2015

\begin{abstract}
Fatty acid composition of individual species of cyanobacteria is conserved and it may be used as a phylogenetic marker. The previously proposed classification system was based solely on biochemical data. Today, new genomic data are available, which support a need to update a previously postulated FA-based classification of cyanobacteria. These changes are necessary in order to adjust and synchronize biochemical, physiological and genomic data, which may help to establish an adequate comprehensive taxonomic system for cyanobacteria in the future. Here, we propose an update to the classification system of cyanobacteria based on their fatty acid composition.
\end{abstract}

Keywords: cyanobacteria; fatty acids; fatty acid desaturases; desaturation; lipids; taxonomy

\section{Introduction}

Cyanobacteria (formerly - blue-green algae) are considered as one of the most ancient groups of living organisms on Earth [1]. Studies of fossil microorganisms in Precambrian rocks (3.5-0.5 billion years ago) indicated the temporal morphological changes in fossil cyanobacterial communities caused by the irreversible changes of physicochemical conditions on Earth [2,3]. Different species of modern cyanobacteria inhabit almost all environments - from soil to fresh and sea waters, as well as such extreme habitats as hot springs, soda and salt lakes, etc. The morphology of some species, especially, extremophilic ones, resemble that found in fossils. Such species are called the relict cyanobacteria $[2,4]$. A comparison of artificial systems consisting of modern prokaryotes, including extremophilic 
cyanobacteria, and Proterozoic forms of cyanobacterial communities suggested that the cyanobacteria are very conservative and have changed insignificantly morphologically and, probably, physiologically during the past, at least, 2 billion years [4]. These negligible changes also refer to the membrane system of cyanobacteria, which is mainly determined by the lipids and fatty acid (FA) species.

The membranes of cyanobacteria are represented by the cytoplasmic (plasma) membrane and thylakoid membranes. Both membranes contain four major glycerolipids: monogalactosyldiacylglycerol (MGDG), digalactosyldiacylglycerol (DGDG), sulfoquinovosyldiacylglycerol (SQDG) and phosphatidylglycerol (PG). The molecular motion of these glycerolipids is determined mainly by the extents of unsaturation of the fatty acids that are esterified to the glycerol backbones [5]. The extent of unsaturation is, in turn, determined by the activity of fatty acid desaturases, the enzymes that introduce double bonds into specific positions of fatty-acyl chains of lipids [6]. Changes in the unsaturation of FAs affect various functions of membrane-bound proteins, such as the photochemical and electron-transport reactions that occur in thylakoid and cytoplasmic membranes of cyanobacterial cells [7].

FA composition of lipids of cyanobacteria is determined by the chain length (number of carbon atoms) and number of double bonds in these chains. In cyanobacteria, the FA chain length usually varies from $\mathrm{C}_{14}$ to $\mathrm{C}_{18}$. The number of double bonds in these chains may vary from 0 to 4 providing fully saturated FAs (with no double bonds), monoenoic (with 1 double bond), dienoic (with 2 double bonds), trienoic and tetraenoic (with 3 and 4 double bonds, respectively) FAs. FA composition of individual species of cyanobacteria is so conserved, that it may be used as a phylogenetic marker [8-10].

The system of classification of cyanobacteria according to their FA composition was proposed by Kenyon [11,12] and improved by Murata and co-workers [13]. According to this Kenyon-Murata classification, all cyanobacterial strains are divided into four distinct groups. Organisms in Group 1 introduce only one double bond at the $\Delta^{9}$ position of fatty acids (usually $\mathrm{C}_{16}$ or $\mathrm{C}_{18}$ FAs) esterified at the $s n-l$ position of the glycerol moiety. In cyanobacteria of Group 2, the $\mathrm{C}_{18}$ stearic acid is desaturated at the $\Delta^{9}, \Delta^{12}$, and $\Delta^{15}[13]$ positions and the $\mathrm{C}_{16}$ palmitic acid is desaturated at the $\Delta^{9}$ and $\Delta^{12}$ positions. In Group 3, the $\mathrm{C}_{18}$ acid is desaturated at the $\Delta^{6}, \Delta^{9}$, and $\Delta^{12}$ positions. Finally, in Group 4 , the $\mathrm{C}_{18}$ stearic acid is desaturated at the $\Delta^{6}, \Delta^{9}, \Delta^{12}$, and $\Delta^{15}$ positions (Table 1) [13].

The available experimental data on desaturation in cyanobacterial cells suggest that the $\Delta 9$-desaturase counts the carbon number from the carboxyl terminus, whereas the so-called $\Delta 15$-desaturase is, in fact, the 13 -desaturase, which counts the carbon number from the methyl-terminus [14]. Although significant progress has been made in understanding the molecular basis of regiospecific desaturation by soluble acyl-acyl-carrier-protein desaturases [15] the counting order of the acyl-lipid membrane-bound $\Delta 12$-desaturase is still under question. It is also important to note that the $\Delta 15(\omega 3)$-desaturase of the cyanobacterium Synechocystis sp. PCC 6803 cannot introduce double bonds into $\Delta^{9}$ monoenoic FAs, and it requires $\Delta^{9,12}$ dienoic substrate for its activity [16]. Here, we will use the $\Delta^{\mathrm{x}}$ abbreviation system to simplify the designations.

Current conclusions on modes of FA desaturation in cyanobacteria are solely based on biochemical analysis of FAs and lipid classes [8-14]. Modern advances in sequencing techniques allowed determination of the whole genomes of various cyanobacterial strains. The genes for the specific acyl-lipid fatty acid desaturases have been identified in many cyanobacterial species [17]. This supports a need to update the previously postulated FA-based classification of cyanobacteria. Here, we propose an updated grouping 
of cyanobacteria, according to their FA composition, based on recent findings in cyanobacterial genomics and biochemistry.

Table 1. Fatty-acid composition of the total lipids from various cyanobacterial strains (adapted from Murata et al. 1992 [13]).

\begin{tabular}{|c|c|c|c|c|c|c|c|c|c|c|c|c|}
\hline \multirow{3}{*}{ Organism } & & \multicolumn{11}{|c|}{ Fatty Acids } \\
\hline & & $14: 0$ & $14: 1$ & $16: 0$ & $16: 1$ & $16: 2$ & 18:0 & $18: 1$ & $18: 2$ & $\alpha 18: 3$ & $\gamma 18: 3$ & $18: 4$ \\
\hline & & & $\Delta^{9}$ & & $\Delta^{9}$ & $\Delta^{9,12}$ & & $\Delta^{9}$ & $\Delta^{9,12}$ & $\Delta^{9,12,15}$ & $\Delta^{6,9,12}$ & $\Delta^{6,9,12,15}$ \\
\hline \multicolumn{13}{|l|}{ Group 1} \\
\hline Mastigocladus laminosus & $\mathrm{F}$ & + & - & + & + & - & + & + & - & - & - & - \\
\hline Synechococcus PCC 7942 & $\mathrm{U}$ & + & - & + & + & - & + & + & - & - & - & - \\
\hline Synechococcus PCC 6301 & $\mathrm{U}$ & + & - & + & + & - & + & + & - & - & - & - \\
\hline Synechococcus lividus & $\mathrm{U}$ & - & - & + & + & - & + & + & - & - & - & - \\
\hline \multicolumn{13}{|l|}{ Group 2} \\
\hline Plectonema boryanum & $\mathrm{F}$ & + & - & + & + & - & + & + & + & + & - & - \\
\hline Nostoc muscorum & $\mathrm{F}$ & + & - & + & + & - & + & + & + & + & - & - \\
\hline Anabaena variabilis & $\mathrm{F}$ & - & - & + & + & + & + & + & + & + & - & - \\
\hline Synechococcus PCC 7002 & $\mathrm{U}$ & + & - & + & + & - & + & + & + & + & - & - \\
\hline \multicolumn{13}{|l|}{ Group 3} \\
\hline Arthrospira platensis & $\mathrm{F}$ & + & + & + & + & - & + & + & + & - & + & - \\
\hline Synechocystis PCC 6714 & $\mathrm{U}$ & + & + & + & + & - & + & + & + & - & + & - \\
\hline \multicolumn{13}{|l|}{ Group 4} \\
\hline Tolypothrix tenius & $\mathrm{F}$ & - & - & + & + & - & + & + & + & + & + & + \\
\hline Synechocystis PCC 6803 & $\mathrm{U}$ & - & - & + & + & - & + & + & + & + & + & + \\
\hline
\end{tabular}

PCC-Number in Pasteur Culture Collection. F-filamentous species; U-unicellulae species.

\section{Results and Discussion}

\subsection{Cyanobacteria of Group 1}

The organisms of Group 1 synthesize only monoenoic FAs usually desaturated at $\Delta^{9}$ position. This group is presented by mesophilic and thermophilic strains of unicellular freshwater Synechococcus and Cyanobacterium, as well as by ramified filamentous heterocystous thermophilic Mastigocladus laminosus $[18,19]$. Previously, it was suggested that the number of double bonds in FA chains correlates with complexity of cyanobacterial cells [10-12], and filamentous strains are not distributed in Group 1. However, it appeared that Mastigocladus laminosus also belongs to Group $1[13,20]$. Thus, organisms that synthesize monoenoic fatty acids (usually, $14: 1 \Delta^{9}, 16: 1 \Delta^{9}$, and $18: 1 \Delta^{9}$ ) may be represented by unicellular and filamentous species (Table 2).

Genomic sequencing and biochemical analysis revealed that desaturation at $\Delta^{9}$ position may be performed by different isozymes of $\Delta 9$-desaturase. Some of these isozymes may be specific to $s n-1$ or $s n-2$ positions of the glycerol moiety [21]. 
Table 2. An updated classification of cyanobacteria on the basis of their fatty acid composition.

\begin{tabular}{|c|c|c|c|c|c|c|c|c|c|c|c|}
\hline \multirow{3}{*}{ Organism } & \multicolumn{11}{|c|}{ Fatty Acids } \\
\hline & $14: 0$ & $14: 1$ & $16: 0$ & $16: 1$ & $16: 2^{\mathrm{e}}$ & $18: 0$ & $18: 1$ & $18: 2$ & $\alpha 18: 3$ & $\gamma 18: 3$ & $18: 4$ \\
\hline & & $\Delta^{9}$ & & $\Delta^{9}$ & $\Delta^{9,12}$ & & $\Delta^{9}$ & $\Delta^{9,12}$ & $\Delta^{9,12,15}$ & $\Delta^{6,9,12}$ & $\Delta^{6,9,12,15}$ \\
\hline \multicolumn{12}{|l|}{ Group 1} \\
\hline $\begin{array}{l}\text { Synechococcus elongatus } \\
\text { PCC } 7942^{\text {a }}\end{array}$ & - & - & + & + & - & + & + & - & - & - & - \\
\hline Mastigocladus laminosus & - & - & + & + & - & + & + & - & - & - & - \\
\hline Synechococcus lividus & - & - & + & + & - & + & + & - & - & - & - \\
\hline Synechococcus vulcanus & + & + & + & + & - & + & + & - & - & - & - \\
\hline $\begin{array}{l}\text { Cyanobacterium stanieri } \\
\text { PCC } 7202^{\text {a }}\end{array}$ & - & - & + & + & - & + & + & - & - & - & - \\
\hline Cyanobacterium sp. B-1200 b & + & + & + & + & - & + & + & - & - & - & - \\
\hline Synechococcus cedrorum & - & - & + & + & - & + & + & - & - & - & - \\
\hline
\end{tabular}

\section{Group 2}

Prochlorococcus marinus ${ }^{\mathrm{c}}$ Synechococcus sp. (marine) ${ }^{\mathrm{d}}$ Prochlorothrix hollandica ${ }^{\mathrm{e}}$

$\begin{array}{llllllll}- & - & + & + & + & + & + & + \\ - & - & + & + & - & + & + & + \\ + & + & + & + & + & + & + & +\end{array}$

\section{Group $3 \alpha$}

Leptolyngbya boryana

Nostoc sp.

Anabaena sp. ${ }^{\mathrm{f}}$

Synechococcus sp. PCC $7002^{\text {a }}$

Gloeobacter violaceus

Trichodesmium erythraeum

\section{Group $3 \gamma$}

Arthrospira platensis B-256 ${ }^{\mathrm{b}}$

Synechocystis sp. PCC $6714^{\text {a }}$

Synechocystis sp. B-274 ${ }^{\text {b }}$

$\begin{array}{llll}- & - & + & + \\ - & - & + & + \\ - & - & + & + \\ - & - & + & + \\ - & - & + & + \\ - & - & + & +\end{array}$

$\begin{array}{ccc}+ & - & + \\ + & - & + \\ + & - & + \\ + & - & + \\ + & - & + \\ + & - & +\end{array}$

$\begin{array}{ccc}+ & + & + \\ + & + & + \\ + & + & + \\ + & + & + \\ + & + & + \\ + & + & +\end{array}$

$\begin{array}{cccccccccccc}+ & - & + & + & - & + & + & + & - & + & - \\ - & - & + & + & - & + & + & + & - & + & - \\ - & - & + & + & + & + & + & + & - & + & -\end{array}$

\section{Group 4}

Tolypothrix tenius

Synechocystis sp. PCC $6803^{\text {a }}$

Lyngbya sp. PCC $8106^{\text {a }}$

Nodularia spumigena

\begin{tabular}{lllllllllllll}
+ & + & + & + & + & + & + & + & + & + & + \\
- & - & + & + & - & + & + & + & + & + & + \\
- & - & + & + & - & + & + & + & + & + & + \\
- & - & + & + & - & + & + & + & + & + & + \\
\hline
\end{tabular}

${ }^{a}$ Number in Pasteur Culture Collection (PCC); ${ }^{b}$ Number in the Collection of Microalgae and Cyanobacteria of the Institute of Plant Physiology RAS (IPPAS); ${ }^{\mathrm{c}}$ Prochlorococcus strains NATL1A, MIT 9211, MIT 9301, MIT 9303, MIT 9312, MIT 9313, MIT 9515, AS9601, CCMP1375, CCMP1986, etc; d Marine species of Synechococcus: strains BL107, CC9311, CC9605, CC9902, RCC307, RS9917, WH5701, WH7805, WH8102, etc.; e Prochlorothrix hollandica was reported to have $\Delta 9$ - and $\Delta 4$-desaturase activities [22]; ${ }^{\mathrm{f}}$ At least, 9 species of Anabaena were studied [23].

The presence of six genes for the $\Delta 9$-desaturases in the genome of Gloeobacter violaceus [24] suggests that some isozymes may be specific both to the sn-position and to the carbon chain length of FAs. Since Nostoc [21] and Gloeobacter [24] do not belong to Group 1, one may suggest that multiple isoforms of the $\Delta 9$-desaturase are not typical to cyanobacteria of Group 1 . Indeed, the type strains of unicellular freshwater Synechococcus, Synechococcus elongatus PCC 7942 (NCBI Reference Sequence 
NC_007604) and Synechococcus elongatus PCC 6301 (NC_006576), each have only one gene for the $\Delta 9$-desaturase. The appearance of $18: 1 \Delta^{9}$ and $16: 1 \Delta^{9}$ at $s n-1$ and $s n-2$ in these two strains [13] suggests that their $\Delta 9$-desaturases are not specific to the chain length of FAs and to the sn-position. However, the genome of a thermophilic unicellular cyanobacterium, Thermosynechococcus elongatus (similarly to filamentous Nostoc [21], and unusual unicellular "single-membrane" organism, Gloeobacter [24]) also carries several copies (three) of a gene for the $\Delta 9$-desaturase.

The alignment of amino acid sequences of $\Delta 9$-desaturases from various strains of cyanobacteria revealed that these enzymes can be classified into three groups (Figure 1). The first group, DesC1, is represented by the enzymes that are similar to the $\Delta 9$-desaturase, which is specific to $s n-1$ position of glycerolipids in Synechocystis sp. PCC 6803 and Anabaena variabilis [25]. Second group, DesC2, forms a cluster of enzymes homologous to the $\Delta 9$-desaturase, which is specific to $s n$-2 position in Antarctic Nostoc sp. 36 [21]. Differences in specificity of DesC1 and DesC2 to sn-position were demonstrated in accurate biochemical experiments [21,25]. The third distinct group of $\Delta 9$-desaturases, DesC3, is clustered by four amino acid sequences that were deduced from the genomic data of Gloeobacter violaceus [24] and two sequences of other cyanobacterial species.

At least four conservative His-containing domains found in these three groups of $\Delta 9$-desaturases. DesC1 and DesC2 were more similar to each other in amino acid sequences than DesC3 (Figure 1). First, second, and fourth His-containing domains (HRLXXHRSF, GHRXHH, GESWHNNHHA) are rather conservative in all three groups of $\Delta 9$-desaturases. The major differences in amino and sequences were observed in the domain 3 of DesC3 if compared to DesC1 and DesC2. The latter two have a very conservative third domain HFTWFVNSATH, while DesC3 has no His residues in this region. Conservative histidine residues function as coordinators of a diiron cluster in the active center of a desaturase that performs dehydrogenation reactions resulting in the formation of double bonds in the FA chains. Therefore, the positioning of His residues affects the specificity of FA desaturases in terms of a chain length and a position of desaturation [26]. The structural basis for positional specificity of desaturases is unknown. It might appear that the ability of desaturases to recognize a certain sn-position is similar to that of glycerolipid acyltransferases, in which a $\mathrm{H}(\mathrm{X})_{4} \mathrm{D}$ motif is a critical component for the enzyme's activity [27].

The specificity of DesC1 and DesC2 to $s n-1$ and $s n-2$ positions have been documented [21,25], the specificity of DesC3 group of $\Delta 9$-desaturases was not studied experimentally. Therefore, the exact function of this type of enzymes is unknown. Chi et al. [17] found that this group of desaturases resembles a large family of membrane-associated $\Delta 5$ - or $\Delta 9$-desaturases. Analysis of FA composition of Gloeobacter violaceus did not reveal any $\Delta 5$-desaturated FAs [28,29]. So, this should be some $\Delta 9$-desaturase with yet unraveled activity and specificity. 


\section{Accession number}

Species

WP 010873728 Synechooystis sp. PCC 6803 WP 010995768 Anabaena sp. PCC 7120

YP_007164144 Cyanobacterium stanieri PCC 7202 WP 002733282 Microoystis aeruginosa PCC 7005 WP 006199118 Nociularia spumigena CCY9419 WP 006616281 Arthrospira platensis NIES-39 WP 006633584 Microcoleus vaginatus FGP-2 WP_011141235 Gloeobacter violaceus PCC 7421 WP 011320892 Anabaena variabilis ATCC 29413 WP_011611109 Trichodesmium erythraeum IMS101 WP_012412456 Nostoo punotiforme PCC 73102 WP_015170515 Geitlerinema sp. PCC 7407 WP_015177398 Oscillatoria nigro-viridis PCC 7112 WP_015217907 Cyanobacterium aponinum PCC 10605 WP_021836317 Crocosphaera vatsoni1 WH 0401

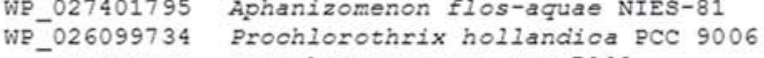
AAB61353 Synechoooccus sp. PCC 7002

YP_401578 Synechoooccus elongatus PCC 7942

CAF18426 Nostoo sp. 36

AAD00699 Thermosynechococous vuloanus WP_026734531 Fischerella sp. PCC 9605 WP_011057556 Thermosynechococous elongatus BP-1 WP_012307598 Synechococcus sp. PCC 7002 WP_015171756 Geitlerinema sp. PCC 7407 WP_015172022 WP_01517526 WP_-015186765 WP_ 01728672 WP_-02614890 Osolllatorta nigro-viridis PCC 7112 Gloeocapsa sp. PCC 7428 Leptolyngbya boryana PCC 6306 25evianabaena $9 \mathrm{p}$.

WP_01114286 WP_011141944 WP_ 011141938 WP_008184032 Moorea producens 3I Goeobacter violaceus PCC 742 Gloebacter violaceus pco 7421 WP_008184032 Moorea producens 3I

\section{Amino acid sequence}

Domain $\mathrm{H} 1$

Domain $\mathrm{H} 2$

FSWRAV GMAFLLYV ITGG I IT L FFHRCI SHRSFNVPKWLEYI FVI CGTLACQG GVFEWVGLHRMHHRESDTT PDPHD SNK-GFWWSHIGW

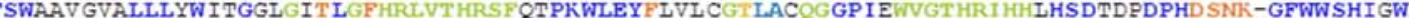
FSWGAV GLFEVLYWLTACI IT LGPHRLVS HRSPETPKWLEYLLVL CGSLACOG GP IQWVGL HRVHHRESDHD GDPHD SNK -GFWWSHMGW

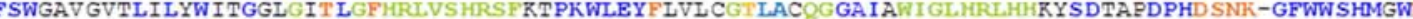
SWNAV GVALLLYWITGGIGITLGFHRLVTHRSF QTPKWLEYFIVECGTLACOGGPIENIGTHRIHHVHSDTDPDPHD SNK-GFWWSHIGW

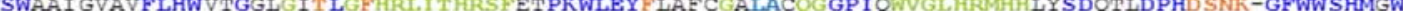

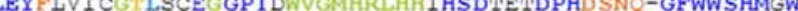
SWA FSWTAV GLALLLHWVTGGLGITLGFHRMLTHRSFRTPKWLEYF IFCG LACEG GVCDWVGLHRI HHQHSDNEQDPHD SHR-GFWWSHMGW

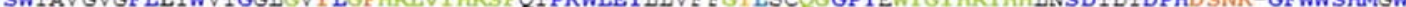

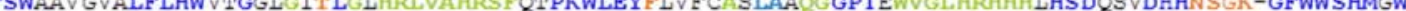

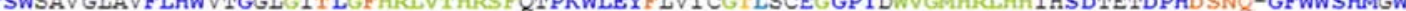
FWGAV GITAFLYWLTACI GVTL LYHRLVSHRSFETPKWLEYPLVFCG LACEG GP I SWVGLHRTHHRYSDHEGDPHD SNK -GFWWSHMGW SWWAV GVTLLLYWVTGAIGITLGFHRLVSHRSFNSPKWLEYLIVFFGILACOG GPIQWVGLFRTHHKYSDTEPDPHD SNK-GFWWSHMAW FSWQAV GVALLLYWVTGGLGITL YYHRLVTHRSP QTPKWLEYVIVI FG LSCEGGPIEWVGTHRIHHLHSDTESDPHD SNQ-GFWWSHMGWSWYAVALALFMHWFTGCLGITLGWHRLISHRSF QVPKWLEYF FVFCGSLSC S GPIENIGLHRHHAAYSDQED HHNSNK-GFWWSHANW

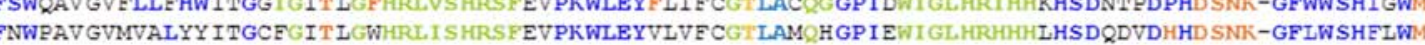

FSWSALGLLVFLHWLFGS IGICLGYHRLLSHRSFQVPKWLEYAIAL I GALALQGGP IFWVGGRQHHAHTEDIDLDPY SAQRGFWWSHILW SFQVPQWLEYVIAVVGALAMOG GPI FWVAGHRTHHAHT EDEIKDPY SARRGFWWSHMLW

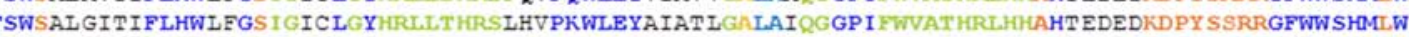
FSWSALAVTIFLHWLFGSIGICLGYHRLLSHRSPVPPQWLEYVIAVVGILAMQG GP IFWVAGHRLHHAHTEDEIKDPY SARRGFWWSHMLW:

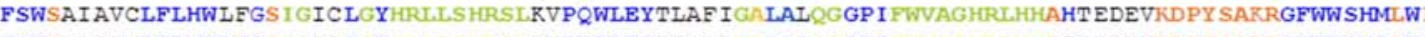
FSWSAIGVMLFLHWIFGS IGICLGYHRLWSHRSLRVPK PLEYT FGLLGALALGGP IFWVAGHRLHHAFTEDVHKDPY SARRGFWWSHIW.

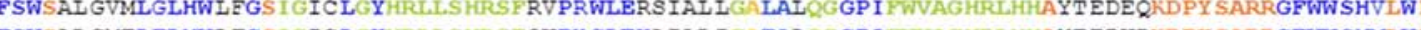

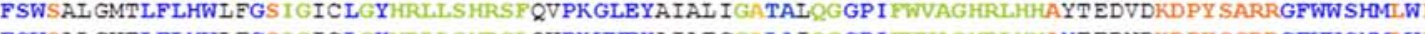

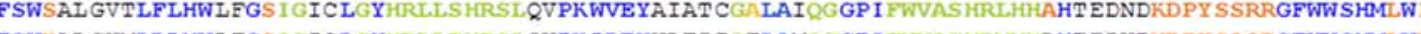
FSWKAL GVMLLLHWLFGS IGICL YHRLLT HRS QVPK PLEYVLTI I GTLAMQG GP I FWVAGHRMHHIHTEDVDND PY SAQRGFWWSHMLW

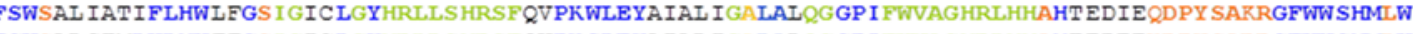
Gloebacter Violaceus PCC 742

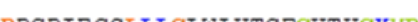
PRGMEVG

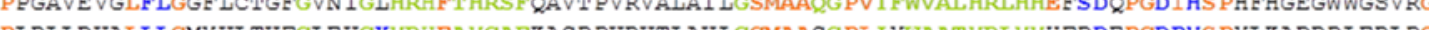

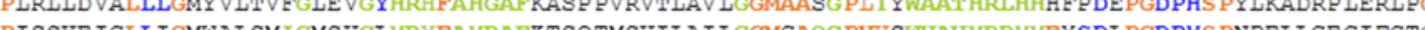

AA

count

129

Figure 1. Cont. 
Domain $\mathrm{H} 3$

Domain $\mathrm{H} 4$

\begin{tabular}{|c|c|}
\hline & \\
\hline WE_010995768 & Anabaena sp. PCC 7120 Cyanobacterium \\
\hline YP_-007164144 & stanieri PCC 7202 \\
\hline Wะ 002733282 & Microoystis aeruginosa PCC 7005 \\
\hline WP_-006199118 & Nodularia_spumigena CCY9419 \\
\hline WP_-006616281 & Arthrospira platensis NIE-39 \\
\hline WP_-006633584 & Microcoleus vaginatus FGP- 2 \\
\hline WP_-011141235 & Gloeobacter_violaceus PCC 7421 \\
\hline WP_- 011320892 & Anabaena variabilis ATCC 29413 \\
\hline WP_011611109 & Trichodesmium_erythraeum IMS101 \\
\hline WP_-012412456 & Nostoo_punctiforme PCC 73102 \\
\hline WP_015170515 & Geitlerinema sp. PCC 7407 \\
\hline WP_015177398 & Oscillatoria nigro-viridis pCC7112 \\
\hline WE_-015217907 & Cyanobacterium aponinum PCC 10605 \\
\hline WP_021836317 & Crocosphaera watsoni1 WH0401 \\
\hline WP_-027401795 & Aphanizomenon flos-aquae NIES- 81 \\
\hline WP_-026099734 & Prochlorothrix hollandica PCC 9006 \\
\hline AAB 61353 & Synechococous sp. PCC 7002 \\
\hline YP_401578 & Synechooocous elongatus PCC 7942 \\
\hline CAF18426 & Nostoc \\
\hline AAD00699 & Thermosynechococous vulcanus \\
\hline VP_ 026734531 & Fischerella sp. PCC 9605 \\
\hline WP_-011057556 & Thermosynechococous elongatus BP-1 \\
\hline WE_-012307598 & Synechococcus sp. PCC 7002 \\
\hline WP-015171756 & Geitlerinema sp. PCC 7407 \\
\hline WP_-015172022 & Geitlerinema sp. PCC 7407 \\
\hline WP_o15175264 & Osoillatoria nigro-viridisPCC 71 \\
\hline WP-015186765 & Gloeocapsa sp. PCC 7428 \\
\hline WE_-017286722 & Leptolyngbya boryana PCC 63 \\
\hline WP_019499810 & Pseudanabaena sp. PCC 6802 \\
\hline WP_-026148909 & Leptolyngbya boryana PCC 6306 \\
\hline WP_01114: & 2s PCC 7421 \\
\hline Wะ_011141938 & Gloeobacter violaceus PCC 7421 \\
\hline 011141944 & Gloeobacter \\
\hline AAS98775 & Lyngbya majuscula \\
\hline 008184032 & Moorea producens 3I \\
\hline
\end{tabular}

GWPFVIWGIFVRLVFVFHETWF VNSAT WKFGYVSHESNDYSRNCWWVALT FGEGWHNNHAYQYSARHGLQWWEVDITWMTI RELSLIGTARDIKLPP GWSFVVWGVF FR IVWVYHCTWLVNSAT FK FGYRTYDAGDRSTNCWWVAVLVF GEGWHNNHHAFOYSAR HGLENWE VDLTWMTV QL OILGIATNVKIAD

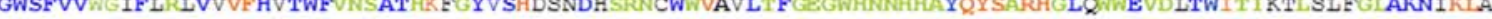

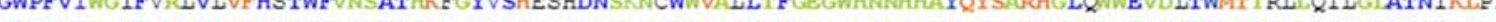
GWSFVVWGVFARIVWVYHCTWLVNSATHKFGYRSYDSGDRSINCWWVAVLVFGEGWTINAHAFQYSARHGLEWWE IDITWMTVQILQSLGTATNVKLAA

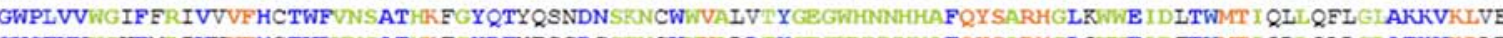

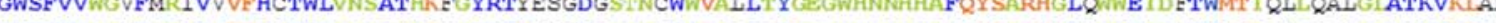

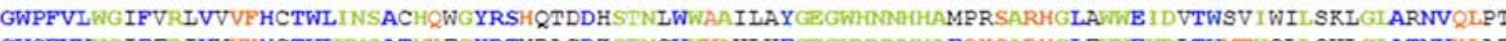
GWSFV GWTPVW GWTE GW GWSFVY

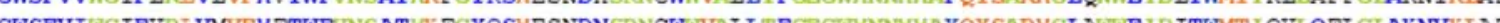
GWPVY TFV TWYYHCTWW

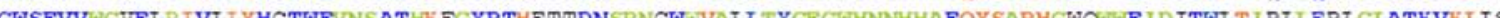

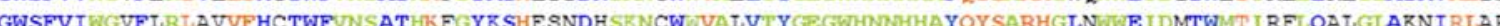

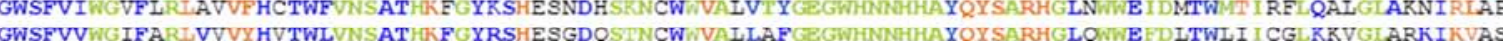

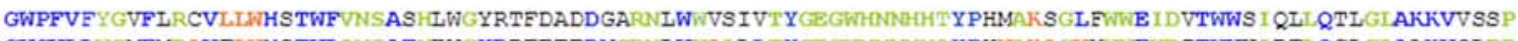

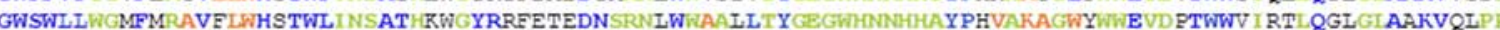

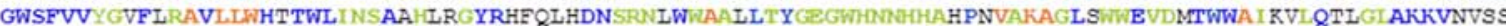

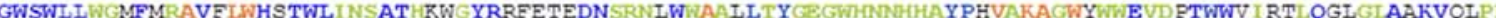

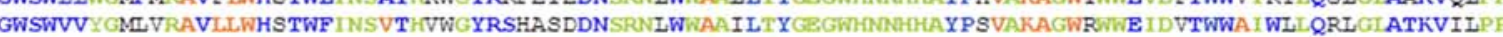

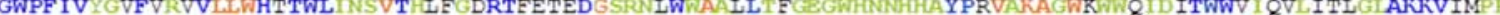

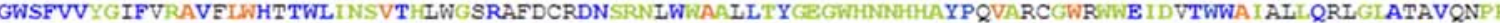

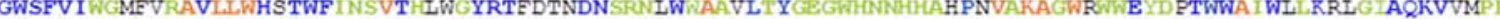

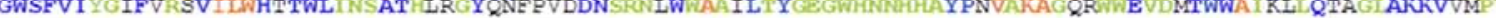

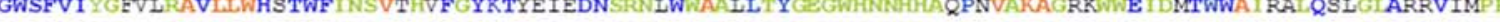

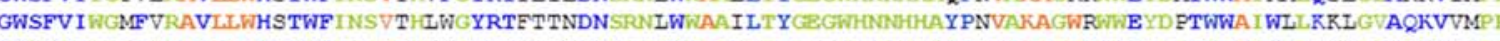

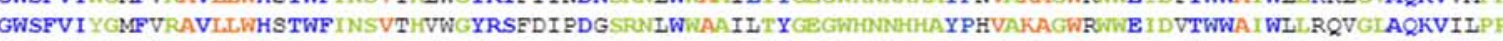

LIIGFLWGGAVRMFVL GNI IWSINS FL HSF GRRIFATREHSRNSGWLALASFGESWHNNHAFPTSASEGLDWYRTD PGYWLI WLIARLGIAWDVK

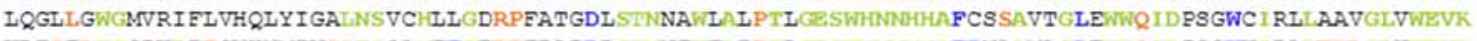

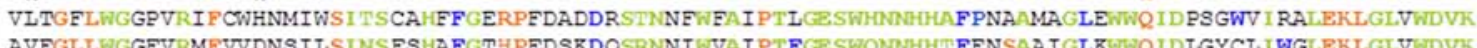

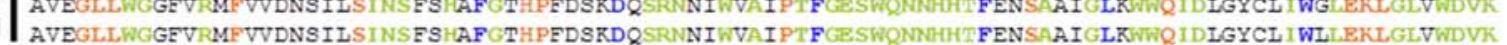

Figure 1. Alignment of partial amino acid sequences of the acyl-lipid fatty acid $\Delta 9$-desaturases from different cyanobacteria. The desaturases are clustered into three types of enzymes, DesC1, DesC2, and DesC3, according to their amino acid and functional features. Four conservative histidine-containing domains are marked. Amino acids identical or similar in all three groups of the $\Delta 9$-desaturases are shown in green; amino acids identical in two groups of desaturases are shown in blue; amino acids, which are unique for one of the desaturase groups, are shown in orange. 


\subsection{Cyanobacteria of Group 2}

Previously, cyanobacteria that produce only mono- and dienoic FAs were unknown [13]. Therefore, Group 2 contained cyanobacteria capable of producing trienoic $\alpha$-linolenic acid, 18:3 $\Delta^{9,12,15}$ (Anabaena, Nostoc, Gloeobacter violaceus, etc.). Now we know a number of organisms that desaturate $\mathrm{C}_{18}$ and $\mathrm{C}_{16}$ FAs at positions $\Delta^{9}$ and $\Delta^{12}$ to produce mono- and dienoic fatty acids.

Genomes of these organisms contain genes for $\Delta 9$ - and $\Delta 12$-desaturases. These are, mainly, representatives of marine species, Prochlorococcus and Synechococcus. We propose to allocate these cyanobacteria into Group 2 (Table 2). The analysis of lipids and FA composition of these organisms is still limited and requires detailed studies. In some plant, fungi, protist, and animal species, FA desaturases may possess bifunctional activities; one enzyme may catalyze two reactions, for example, the formation of double bonds at $\Delta^{12}$ and $\omega^{3}\left(\Delta^{15}\right)$ positions [22,30]. Such bifunctional enzymes have not been yet reported in cyanobacteria. However, to confirm their absence, more experimental evidence is necessary on lipids and FAs for cyanobacteria of Group 2.

The freshwater filamentous Prochlorothrix hollandica differs from other cyanobacteria by the presence of light-harvesting chlorophyll $a / b$ binding antenna and by the absence of phycobilins. Prochlorothrix hollandica is known as a $\mathrm{C}_{14}$-rich organism, which contains $5 \%$ of $14: 0$ and $30 \%$ of $14: 1 \Delta^{9}$ in lipids [31]. Prochlorothrix, together with $\Delta 9$-desaturase, has the unique $\Delta 4$-desaturase activity and produces unusual 16:1 $\Delta^{4}(25 \%)$ and $16: 2 \Delta^{4,9}(10 \%)$ FAs [31]. The genetic data for the cyanobacterial $\Delta 4$-desaturase is still unavailable. Nevertheless, the presence of high amounts of $16: 2 \Delta^{4,9}$ (and the complete absence of 18:2 FAs) should place Prochlorothrix hollandica to a special position in Group 2 of cyanobacteria, which are capable of synthesizing the dienoic FAs.

\subsection{Cyanobacteria of Group 3}

According to previously proposed classification, the cyanobacterial strains that synthesize trienoic $\alpha$-linolenic acid, 18:3 $\Delta^{9,12,15}$ were assigned to Group 2. These organisms have three distinct FA desaturase activities: $\Delta 9-, \Delta 12-$ and $\Delta 15$-desaturases. Organisms of a former Group 3 also have three distinct desaturases, but, instead of $\Delta 15$, they introduce a third double bond at position $\Delta^{6}$ and produce trienoic $\gamma$-linolenic acid, $18: 3 \Delta^{6,9,12}$, as a final product of desaturation.

We propose to combine all organisms that produce trienoic FAs as the final products of desaturation

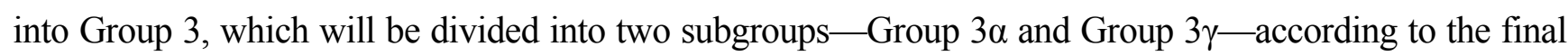
product of desaturation- $\alpha$ - or $\gamma$-linolenic acids (Table 2 ).

Cyanobacteria that belong to a newly proposed Group $3 \alpha$ produce $\alpha$-linolenic acid, 18:3 $\Delta^{9,12,15}$. These species (Leptolyngbya boryana (formerly, Plectonema boryanum), Gloeobacter violaceus, Anabaena sp., Synechococcus sp. PCC 7002, Trichodesmium erythraeum, some Nostoc species) are characterized both genetically and biochemically.

Genome sequencing of these species confirmed the presence of genes for the specific $\Delta 9-, \Delta 12-$, and $\Delta 15$-desaturases [24,32-34]. Lipid and FA analysis revealed the presence of 16:0, 16:1 $\Delta^{9}, 18: 0$,

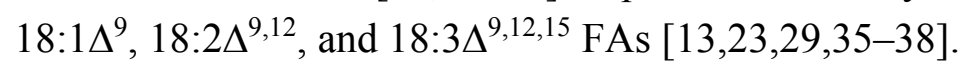

The presence of a single strain of marine Synechococcus in this group (namely, Synechococcus sp. PCC 7002) raises a question about possible diversity of this genus in terms of FA composition. Table 2 
clearly demonstrates that freshwater Synechococcus strains synthesize monoenoic FAs and belong to Group 1, whereas marine Synechococcus strains synthesize dienoic FAs and belong to Group 2. Alternatively, it may raise a question about the correct assignment of a strain PCC 7002 to a genus of Synechococcus.

Cyanobacteria of Group $3 \gamma$ are capable of synthesizing the $\gamma$-linolenic acid, 18:3 $\Delta^{6,9,12}$. These organisms have three distinct FA desaturase activities: $\Delta 6-, \Delta 9$ - and $\Delta 12$-desaturases. These cyanobacteria are represented by species of filamentous Arthrospira (Spirulina), unicellular Synechocystis sp. PCC 6714, and Synechocystis sp. IPPAS B-274.

The genomic and biochemical data for Arthrospira [29,39-41] and Synechocystis sp. PCC 6714 [13,42] are available, which support the positioning of these strains to Group 3. Synechocystis strains PCC 6714 and PCC 6803 are thought to be closely related species [42]. However, unlike Synechocystis PCC 6803 (Group 4, see below), Synechocystis sp. PCC 6714 lacks a gene for the $\omega 3(\Delta 15)$-desaturase [42], and it cannot synthesize $\alpha$-linolenic and/or stearidonic acid.

\subsection{Cyanobacteria of Group 4}

Cyanobacteria of Group 4 have four acyl-lipid fatty acid desaturases and they can synthesize tetraenoic

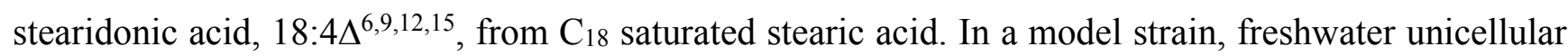
Synechocystis sp. PCC 6803, synthesis of $\alpha$-linolenic and stearidonic acids is temperature-dependent and occurs only at low temperatures $\left(15-25^{\circ} \mathrm{C}\right)$ [43]. Therefore, biochemical analysis cannot reveal 18:3 $\alpha$ and 18:4 FAs in cells grown at optimal temperatures $\left(30-36^{\circ} \mathrm{C}\right)$. Genome sequencing [44] together with gene expression analysis [45] demonstrated the presence and expression of genes for $\Delta 6-, \Delta 9-, \Delta 12-$, and $\Delta 15(\omega 3)$-desaturases in Synechocystis sp. PCC 6803. And besides, the gene for $\Delta 15(\omega 3)$-desaturase was active only at low temperatures [45].

Similarly, genome sequence analysis of the marine filamentous cyanobacteria Nodularia spumigena and Lyngbya sp. PCC 8106 revealed the presence of genes for $\Delta 6-, \Delta 9-, \Delta 12-$, and $\Delta 15(\omega 3)$-desaturases [17]. Thus, these cyanobacteria would potentially produce $\alpha$-linolenic, $\gamma$-linolenic, and stearidonic acids, the latter as a final product of desaturation.

Solid biochemical evidence is available for freshwater filamentous Tolypothrix species that confirms the presence of tri- and tetraenoic $\mathrm{C}_{18}$ FAs $[12,13,29]$. Recent lipid analysis of two strains, Tolypothrix tenuis and Tolypothrix distorta revealed previously undetected positional isomer of stearidonic acid, 18:4 $\Delta^{3,6,9,12}$ [46]. This so-called, $\gamma$-stearidonic acid was present in cells nearly in trace amounts. If this data is confirmed, it would be challenging to find a new cyanobacterial desaturase with $\Delta^{3}$ specificity. The complete genomic sequence of Tolypothrix may clarify whether a fifth, yet unknown, desaturase exists in cyanobacteria, or a double bond at position $\Delta^{3}$ is formed due to non-specific activity of $\Delta 15(\omega 3)$-desaturase on $\mathrm{C}_{16} \mathrm{FA}$, which is further elongated to $\mathrm{C}_{18}$.

\subsection{Adaptive and Taxonomic Impact of Cyanobacterial Fatty Acid Composition}

Cyanobacteria are characterized by rather limited set of FAs in their lipids: $\mathrm{C}_{14}-\mathrm{C}_{18}$ FAs with $1-4$ double bonds. However, they have diverse phenotypes, and they inhabit very diverse environments, which, in many cases, are highly extreme. Fatty acid composition can be used to characterize different species of cyanobacteria, although the exact taxonomic meaning of FA composition is not completely 
understood. The organization or complexity of cyanobacterial cells (unicellular or filamentous) does not correlate with FA composition. A number of double bonds in FAs correlates instead with temperature of the environment. Thermophilic unicellular species usually have monoenoic FAs, whereas mesophilic or psychrophilic unicellular species produce polyunsaturated FAs, which help them to survive at low temperatures by adjusting the membrane fluidity [7]. Thermophilic filamentous species adjust the membrane fluidity by the inhibition of 16:0 acid elongation and by enhancement of the monoenoic 16:1 acid synthesis [29]. In mesophilic species, both mechanisms-accumulation of 16:1 and desaturation - may be active. In mesophilic filamentous Anabaena variabilis, a drop in temperature leads to accumulation of $\mathrm{C}_{16}$ in the dark, and to formation of polyunsaturated FAs (mainly, $\mathrm{C}_{18}$ ) in the light $[29,47]$.

Fatty acid composition may be used to clarify the taxonomic position of a certain cyanobacterial strain. Thus, for example, it is rather surprising to find the representatives of genus Synechococcus (Synechococcus sp. PCC 7002) in diverse Groups 1, 2, and 3. Several authors noticed that the strains comprising the Synechococcus genus seem to be polyphyletic, and they suggested that this genus should be separated into different groups $[48,49]$.

In general, the taxonomy of cyanobacteria is complicated and unclear [19,50]. The easiest and mostly used profiling technique employs the 16S rRNA gene sequence clustering. However, this simplified approach often leads to false assignments of strains and incorrect annotations. A more promising way to classify cyanobacterial strains is a polyphasic approach, which takes into consideration molecular, morphological, biochemical, and physiological characteristics of individual cultures and strains $[51,52]$. Recent developments in genome sequencing techniques provide a powerful tool for genetic profiling of cyanobacterial strains implying that sequence annotations are accurate. In such a polyphasic approach, the fatty acid composition is still a valuable marker to the cyanobacterial taxonomy.

\section{Conclusions}

The taxonomic system of cyanobacteria is developing according to combined multiple markers, including molecular, biochemical, ultrastructural, phenotypic and ecological data. The previously proposed system of biochemical classification of cyanobacteria according to their FA composition [11-13] is also changing. Here, we propose an update to this system according to newly available genomic and biochemical data. The basis of the system remains unchanged: cyanobacteria are grouped according the number of double bonds in their FAs. The major improvements are as follows. (1) The replacement of organisms in a previous "Group 2" with a new "Group 2" represented mainly by marine unicellular species, which are characterized by the presence of $\Delta 9$ - and $\Delta 12$-desaturases and are capable of producing 16:2 or 18:2 FAs as the final product of FA desaturation. (2) Organisms previously assigned to Group 2 are transferred into Group 3, Subgroup 3 $\alpha$. Strains in this group are characterized by the presence of $\Delta 9-, \Delta 12-$, and $\Delta 15(\omega 3)$-desaturases, and they synthesize 18:3 $\alpha$-linolenic acid as a final product of FA desaturation. (3) Organisms of the former "Group 3" (they have $\Delta 6-, \Delta 9-$, and $\Delta 12$-desaturases, and they synthesize 18:3 $\gamma$-linolenic acid) remain in Group 3, but placed into Subgroup $3 \gamma$. Group 1 (includes organisms that have $\Delta 9$-desaturase(s) and produce only monounsaturated FAs), and Group 4 (organisms with four FA desaturases, namely $\Delta 6-, \Delta 9-, \Delta 12-$, and $\Delta 15(\omega 3)$-desaturases, which may synthesize 18:4 stearidonic acid) remain unchanged. 
These changes in FA-based classification system are necessary in order to adjust and synchronize biochemical, physiological and genomic data, which may help to establish an adequate comprehensive taxonomic system for cyanobacteria in the future.

\section{Acknowledgments}

This work was supported by a grant from Russian Science Foundation No. 14-24-00020.

\section{Author Contributions}

Kirill S. Mironov analyzed amino acid and genomic sequence data; Dmitry A. Los designed research and wrote the manuscript. Both authors have read and approved the final manuscript.

\section{Conflicts of Interest}

The authors declare no conflict of interest.

\section{References}

1. Schopf, J.W. Microfossils of the early Archean apex chert: New evidence of the antiquity of life. Science 1993, 260, 640-646.

2. Segreev, V.N.; Gerasimenko, L.M.; Zavarzin, G.A. The Proterozoic history and present state of cyanobacteria. Microbiology 2002, 71, 623-637.

3. Rozanov, A.Y.; Astafieva, M.M. The evolution of the early precambrian geobiological systems. Paleontol. J. 2009, 43, 911-927.

4. Blank, C.E.; Sánchez-Baracaldo, P. Timing of morphological and ecological innovations in the cyanobacteria-A key to understanding the rise in atmospheric oxygen. Geobiology 2010, 8, 1-23.

5. Los, D.A.; Mironov, K.S.; Allakhverdiev, S.I. Regulatory role of membrane fluidity in gene expression and physiological functions. Photosynth. Res. 2013, 116, 489-509.

6. Los, D.A.; Murata, N. Structure and expression of fatty acid desaturases. Biochim. Biophys. Acta 1998, 1394, 3-15.

7. Los, D.A.; Murata, N. Membrane fluidity and its roles in the perception of environmental signals. Biochim. Biophys. Acta 2004, 1666, 142-157.

8. Parker, P.L.; van Baalen, C.; Maurer, L. Fatty acids in eleven species of blue-green algae: Geochemical significance. Science 1967, 155, 707-708.

9. Holton, R.W.; Blecker, H.H.; Stevens, T.S. Fatty acids in blue-green algae: Possible relation to phylogenetic position. Science 1968, 160, 545-547.

10. Kenyon, C.N.; Stanier, R.Y. Possible evolutionary significance of polyunsaturated fatty acids in blue-green algae. Nature 1970, 227, 1164-1166.

11. Kenyon, C.N. Fatty acid composition of unicellular strains of blue-green algae. J. Bacteriol. 1972, 109, 827-834.

12. Kenyon, C.N.; Rippka, R.; Stanier, R.Y. Fatty acid composition and physiological properties of some filamentous blue-green algae. Arch. Microbiol. 1972, 83, 216-236. 
13. Murata, N.; Wada, H.; Gombos, Z. Modes of fatty-acid desaturation in cyanobacteria. Plant Cell Physiol. 1992, 33, 933-941.

14. Higashi, S.; Murata, N. An in vivo study of substrate specificities of acyl-lipid desaturases and acyltransferases in lipid synthesis in Synechocystis PCC 6803. Plant Physiol. 1993, 102, 1275-1278.

15. Guy, J.E.; Whittle, E.; Moche, M.; Lengqvist, J.; Lindqvist, Y.; Shanklin, J. Remote control of regioselectivity in acyl-acyl carrier protein-desaturases. Proc. Natl. Acad. Sci. USA 2011, 108, 16594-16599.

16. Mironov, K.S.; Sidorov, R.A.; Trofimova, M.S.; Bedbenov, V.S.; Tsydendambaev, V.D.; Allakhverdiev, S.I.; Los, D.A. Light-dependent cold-induced fatty acid unsaturation, changes in membrane fluidity, and alterations in gene expression in Synechocystis. Biochim. Biophys. Acta 2012, 1817, 1352-1359.

17. Chi, X.; Yang, Q.; Zhao, F.; Qin, S.; Yang, Y.; Shen, J.; Lin, H. Comparative analysis of fatty acid desaturases in cyanobacterial genomes. Comp. Funct. Genomics 2008, doi:10.1155/2008/284508.

18. Sarsekeyeva, F.K.; Usserbaeva, A.A.; Zayadan, B.K.; Mironov, K.S.; Sidorov, R.A.; Kozlova, A.Y.; Kupriyanova, E.V.; Sinetova, M.A.; Los, D.A. Isolation and characterization of a new cyanobacterial strain with a unique fatty acid composition. Adv. Microbiol. 2014, 4, 1033-1043.

19. Komarek, J.; Kopecky, J.; Cepak, V. Generic characters of the simplest cyanoprokaryotes, Cyanobium, Cyanobacterium and Synechococcus. Cryptogam. Algol. 1999, 20, 209-222.

20. Hirayama, O.; Kishida, T. Temperature-induced changes in the lipid molecular species of a thermophilic cyanobacterium, Mastigocladus laminosus. Agric. Biol. Chem. 1991, 55, 781-785.

21. Chintalapati, S.; Prakash, J.S.; Gupta, P.; Ohtani, S.; Suzuki, I.; Sakamoto, T., Murata, N.; Shivaji, S. A novel $\Delta 9$ acyl-lipid desaturase, DesC2, from cyanobacteria acts on fatty acids esterified to the $s n-2$ position of glycerolipids. Biochem. J. 2006, 398, 207-214.

22. Howard, G.D.; Zhang, H.; Farrall, L.; Ripp, K.G.; Tomb, J.-F.; Hollerbach, D.; Yadav, N.S. Identification of bifunctional $\Delta 12 / \omega 3$ fatty acid desaturases for improving the ratio of $\omega 3$ to $\omega 6$ fatty acids in microbes and plants. Proc. Natl. Acad. Sci. USA 2006, 103, 9446-9451.

23. Shemet, V.; Karduck, P.; Hoven, H.; Grushko, B.; Fischer, W.; Quadakkers, W.J.; Carpenter, E.J.; Harvey, H.R.; Fry, B.; Capone, D.G. Biogeochemical tracers of the marine cyanobacterium Trichodesmium. Deep Sea Res. Part I Oceanogr. Res. Pap. 1997, 44, 27-38.

24. Nakamura, Y.; Kaneko, T.; Sato, S.; Mimuro, M.; Miyashita, H.; Tsuchiya, T.; Sasamoto, S.; Watanabe, A.; Kawashima, K.; Kishida, Y.; et al. Complete genome structure of Gloeobacter violaceus PCC 7421, a cyanobacterium that lacks thylakoids (Supplement). DNA Res. 2003, 10, 181-201.

25. Sakamoto, T.; Wada, H.; Nishida, I.; Ohmori, M.; Murata, N. $\Delta 9$ Acyl-lipid desaturases of cyanobacteria. Molecular cloning and substrate specificities in terms of fatty acids, sn-positions, and polar head groups. J. Biol. Chem. 1994, 269, 25576-25580.

26. Shanklin, J.; Guy, J.E.; Mishra, G.; Lindqvist, Y. Desaturases: Emerging models for understanding functional diversification of diiron-containing enzymes. J. Biol. Chem. 2009, 284, 18559-18563.

27. Turnbull, A.P.; Rafferty, J.B.; Sedelnikova, S.E.; Slabas, A.R.; Schierer, T.P.; Kroon, J.T.M.; Simon, J.W.; Fawcett, T.; Nishida, I.; Murata, N.; et al. Analysis of the structure, substrate specificity, and mechanism of squash glycerol-3-phosphate (1)-acyltransferase. Structure 2001, 9 , $347-353$. 
28. Selstam, E.; Campbell, D. Membrane lipid composition of the unusual cyanobacterium Gloeobacter violaceus sp. PCC 7421, which lacks sulfoquinovosyl diacylglycerol. Arch. Microbiol. 1996, 166, 132-135.

29. Maslova, I.P.; Mouradyan, E.A.; Lapina, S.S.; Klyachko-Gurvich, G.L.; Los, D.A. Lipid fatty acid composition and thermophilicity of cyanobacteria. Russ. J. Plant Physiol. 2004, 51, 353-360.

30. Zhou, X.R.; Green, A.G.; Singh, S.P. Caenorhabditis elegans $\Delta 12$-desaturase FAT-2 is a bifunctional desaturase able to desaturate a diverse range of fatty acid substrates at the $\Delta 12$ and $\Delta 15$ positions. J. Biol. Chem. 2011, 286, 43644-43650.

31. Gombos, Z.; Murata, N. Lipids and fatty acids of Prochlorothrix hollandica. Plant Cell Physiol. 1991, 32, 73-77.

32. Kaneko, T.; Nakamura, Y.; Wolk, C.P.; Kuritz, T.; Sasamoto, S.; Watanabe, A.; Iriguchi, M.; Ishikawa, A.; Kawashima, K.; Kimura, T.; et al. Complete genomic sequence of the filamentous nitrogen-fixing cyanobacterium Anabaena sp. strain PCC 7120. DNA Res. 2001, 8, 205-213.

33. Ludwig, M.; Bryant, D.A. Transcription profiling of the model cyanobacterium Synechococcus sp. strain PCC 7002 by next-gen (SOLiD ${ }^{\mathrm{TM}}$ ) sequencing of cDNA. Front. Microbiol. 2011, 2, doi:10.3389/fmicb.2011.00041.

34. Meeks, J.C.; Elhai, J.; Thiel, T.; Potts, M.; Larimer, F.; Lamerdin, J.; Predki, P.; Atlas, R. An overview of the genome of Nostoc punctiforme, a multicellular, symbiotic cyanobacterium. Photosynth. Res. 2001, 70, 85-106.

35. Li, R.; Watanabe, M.M. Fatty acid composition of planktonic species of Anabaena (Cyanobacteria) with coiled trichomes exhibited a significant taxonomic value. Curr. Microbiol. 2004, 49, 376-380.

36. Sakamoto, T.; Higashi, S.; Wada, H.; Murata, N.; Bryant, D.A. Low-temperature-induced desaturation of fatty acids and expression of desaturase genes in the cyanobacterium Synechococcus sp. PCC 7002. FEMS Microbiol. Lett. 1997, 152, 313-320.

37. Temina, M.; Rezankova, H.; Rezanka, T.; Dembitsky, V.M. Diversity of the fatty acids of the Nostoc species and their statistical analysis. Microbiol. Res. 2007, 162, 308-321.

38. Gugger, M.; Lyra, C.; Suominen, I.; Tsitko, I.; Humbert, J.F.; Salkinoja-Salonen, M.S.; Sivonen, K. Cellular fatty acids as chemotaxonomic markers of the genera Anabaena, Aphanizomenon, Microcystis, Nostoc and Planktothrix (cyanobacteria). Int. J. Syst. Evol. Microbiol . 2002, 52, 1007-1015.

39. Fujisawa, T.; Narikawa, R.; Okamoto, S.; Ehira, S.; Yoshimura, H.; Suzuki, I.; Masuda, T.; Mochimaru, M.; Takaichi, S.; Awai, K.; et al. Genomic structure of an economically important cyanobacterium, Arthrospira (Spirulina) platensis NIES-39. DNA Res. 2010, 17, 85-103.

40. Cheevadhanarak, S.; Paithoonrangsarid, K.; Prommeenate, P.; Kaewngam, W.; Musigkain, A.; Tragoonrung, S.; Tabata, S.; Kaneko, T.; Chaijaruwanich, J.; Sangsrakru, D.; et al. Draft genome sequence of Arthrospira platensis C1 (PCC9438). Stand. Genomic Sci. 2012, 6, 43-53.

41. Deshnium, P.; Paithoonrangsarid, K.; Suphatrakul, A.; Meesapyodsuk, D.; Tanticharoen, M.; Cheevadhanarak, S. Temperature-independent and -dependent expression of desaturase genes in filamentous cyanobacterium Spirulina platensis strain C1 (Arthrospira sp. PCC 9438). FEMS Microbiol. Lett. 2000, 184, 207-213. 
42. Kopf, M.; Klähn, S.; Pade, N.; Weingärtner, C.; Hagemann, M.; Voß, B.; Hess, W.R. Comparative genome analysis of the closely related Synechocystis strains PCC 6714 and PCC 6803. DNA Res. 2014, 21, 255-266.

43. Wada, H.; Murata, N. Temperature-induced changes in the fatty acids composition of the cyanobacterium, Synechocystis PCC 6803. Plant Physiol. 1990, 92, 1062-1069.

44. Kaneko, T.; Sato, S.; Kotani, H.; Tanaka, A.; Asamizu, E.; Nakamura, Y.; Miyajima, N.; Hirosawa, M.; Sugiura, M.; Sasamoto, S.; et al. Sequence analysis of the genome of the unicellular cyanobacterium Synechocystis sp. strain PCC6803. II. Sequence determination of the entire genome and assignment of potential protein-coding regions. DNA Res. 1996, 3, 109-136.

45. Los, D.A.; Ray, M.K.; Murata, N. Differences in the control of the temperature-dependent expression of four genes for desaturases in Synechocystis sp. PCC 6803. Mol. Microbiol. 1997, 25, 1167-1175.

46. Ǩezanka, T.; Lukavský, J.; Siristova, L.; Sigler, K. Regioisomer separation and identification of triacylglycerols containing vaccenic and oleic acids, and $\alpha$ - and $\gamma$-linolenic acids, in thermophilic cyanobacteria Mastigocladus laminosus and Tolypothrix sp. Phytochemistry 2012, 78, 147-155.

47. Sato, N.; Murata, N. Studies on the temperature shift-induced desaturation of fatty acids in monogalactosyl diacylglycerol in the blue-green alga (Cyanobacterium) Anabaena variabilis. Plant Cell Physiol. 1981, 22, 1043-1050.

48. Honda, D.; Yokota, A.; Sugiyama, J. Detection of 7 major evolutionary lineages in cyanobacteria based on the $16 \mathrm{~S}$ ribosomal-RNA gene sequence-analysis with new sequences of 5 marine Synechococcus strains. J. Mol. Evol. 1999, 48, 723-739.

49. Robertson, B.R.; Tezuka, N.; Watanabe, M.M. Phylogenetic analyses of Synechococcus strains (Cyanobacteria) using sequences of 16S rDNA and part of the phycocyanin operon reveal multiple evolutionary lines and reflect phycobilin content. Int. J. Syst. Evol. Microbiol. 2001, 51, 861-871.

50. Oren, A. Cyanobacterial systematics and nomenclature as featured in the International Bulletin of Bacteriological Nomenclature and Taxonomy/International Journal of Systematic Bacteriology/International Journal of Systematic and Evolutionary Microbiology. Int. J. Syst. Evol. Microbiol. 2011, 61, 10-15.

51. Komarek, J. Recent changes (2008) in cyanobacteria taxonomy based on a combination of molecular background with phenotype and ecological consequences (genus and species concept). Hydrobiologia 2010, 639, 245-259.

52. Schwarz, D.; Orf, I.; Kopka, J.; Hagemann, M. Recent applications of metabolomics toward cyanobacteria. Metabolites 2013, 3, 72-100.

(C) 2015 by the authors; licensee MDPI, Basel, Switzerland. This article is an open access article distributed under the terms and conditions of the Creative Commons Attribution license (http://creativecommons.org/licenses/by/4.0/). 